\title{
ANÁLISE DO COMPORTAMENTO DE TIJOLOS ECOLÓGICOS MODULARES DE PAPEL RECICLÁVEL QUANTO À CAPACIDADE DE ABSORÇÃO DE ÁGUA E À DURABILIDADE
}

\section{Behavior analysis of ecological modular bricks of recycled paper as the capacity of water absorption and durability}

\author{
Sergio Rafael Cortes de Oliveira', Raphael Mesquita de Aguiar², Catarini Ressiguier Soares Crespo ${ }^{3}$, João \\ Marcos Gonçalves Barreto ${ }^{4}$, Luisa Gonçalves Barreto ${ }^{5}$
}

Recebido em 20 de abril de 2016; recebido para revisão em 07 de julho de 2016; aceito em 18 de julho de 2016; disponível on-line em 13 de março de 2017.

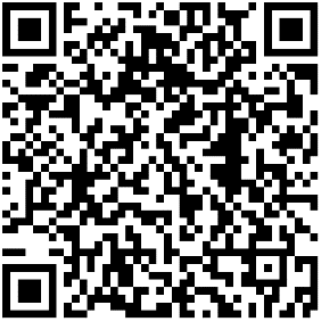

PALAVRAS CHAVE:

Impacto ambiental;

Absorção de água;

Durabilidade de tijolos;

Desgaste de tijolos;

Tijolo de jornal-cimento.

\section{KEYWORDS:}

Environmental impact; Absorption of water; Bricks durability;

Bricks wear;

Newspaper-cement brick.

* Contato com os autores:

${ }^{1}$ e-mail: sergio.oliveira@iff.edu.br (S. R. C de OLIVEIRA)

Engenheiro Civil; Doutor; Docente; Instituto Federal de Educação, Ciência e Tecnologia Fluminense (IFF).

2 e-mail: raphael.aguiar@iff.edu.br (R.M. de AGUIAR)

Arquiteto; Bacharel; Docente; Instituto Federal de Educação, Ciência e Tecnologia Fluminense (IFF).

${ }^{3}$ e-mail: catariniressiguier@hotmail.com (C. R. S. CRESPO)

Estudante de Arquitetura eUrbanismo; Discente; Instituto Federal de Educação, Ciência e Tecnologia Fluminense (IFF)

${ }^{4}$ e-mail: joaomarcusgoncalves@hotmail.com (J. M. G. BARRETO)

Edificações; Técnico; Discente; Instituto Federal de Educação, Ciência e Tecnologia Fluminense (IFF).

5 e-mail: luisagbarreto@hotmail.com (L. G. BARRETO)

Estudante de Letras; Discente; Instituto Federal de Educação, Ciência e Tecnologia Fluminense (IFF). 


\section{INTRODUÇÃO}

A demanda atual da construção civil é por novos materiais e tecnologias não convencionais, a partir do aproveitamento de resíduos sob a perspectiva sustentável, diante do alto consumo de recursos naturais, de água e de energia, além da geração de resíduos e de desperdícios em suas atividades de construção e demolição.

Segundo John (2008), a indústria da construção civil (ICC) é responsável pela utilização de $15 \%$ a $50 \%$ de todo o recurso natural extraído em um país, caracterizando-se como um setor com grande potencial de utilização de resíduos sólidos devido à variedade e grande quantidade de material consumido, além da necessidade de minimização de custos. Estima-se que a produção anual de resíduos de construção e demolição (RCD's) esteja em torno de 45 milhões de toneladas. Em contrapartida, a ICC tem a sua importância socioeconômica na minimização do problema do déficit habitacional e na geração de emprego e renda.

Sabe-se que o tijolo de cerâmica vermelha fabricado pela indústria ceramista tem grande utilização na construção civil. Esse tipo de tijolo é confeccionado com a argila extraída do meio ambiente, que é queimada em fornos nas olarias, gerando impactos ambientais intensos.

Um dos materiais já difundidos que tange a preocupação com as questões ambientais e o desenvolvimento sustentável é o tijolo de solocimento que, apesar de apresentar diversas vantagens, pode ser inviabilizado por uma característica desfavorável do solo, conforme comentado por Lopes (2002).

0 presente trabalho tem como objeto de estudo um material de construção do tipo tijolo modular prensado, feito a partir da mistura de papel reciclável com cimento, tendo como matéria-prima base o jornal, constituindo uma proposição alternativa não convencional e ecologicamente correta, face à minimização da agressividade ao meio ambiente.

Partindo do princípio que a durabilidade dos novos materiais de construção é uma das maiores preocupações que tem relevância na escolha do material a ser empregado em dada aplicação, especialmente por conta da eventual degradação rápida sofrida por alguns, essa propriedade de desempenho tem atenção especial neste trabalho, juntamente com a capacidade de absorção de água.

Apoiando-se em Souza, Segantini e Pereira (2008), o estudo corrobora com a necessidade de preservação ambiental, reconhecendo a tendência de escassez dos recursos naturais e o acúmulo crescente de lixo urbano, apontando a necessidade de novos conceitos e soluções técnicas visando à sustentabilidade das atividades da construção civil. A reciclagem e o aproveitamento de resíduos de construção e até mesmo de outras atividades se destacam como alternativas alinhadas a esses novos conceitos, por buscarem agregar valor aos materiais descartados, atribuindo-Ihes uma nova condição, ainda que possam existir outras aplicações mais adequadas.

\section{OBJETIVO}

Baseando-se no princípio da utilização de materiais não convencionais, este trabalho tem como objetivo a avaliação do comportamento do tijolo modular prensado de papel reciclável, quanto à capacidade de absorção de água e à durabilidade, propriedade medida nos ensaios de molhagem e secagem e no de desgaste utilizando slake durability, apresentando-o como mais uma solução vinculada à redução dos impactos ambientais dos métodos de fabricação dos tijolos convencionais e à minimização dos custos das obras.

\section{REVISÃO BIBLIOGRÁFICA}

$\mathrm{Na}$ literatura há diversos estudos de materiais que utilizam fibras vegetais (como as fibras de celulose), do bagaço da cana-de-açúcar, da casca de arroz, etc. Um estudo relevante é o de Nolasco (1993), que empregou resíduo sólido industrial proveniente do processo de produção do papel para a produção de materiais, tendo avaliado positivamente a eficiência do compósito de cimento e resíduo de papel na fabricação de painéis de divisórias, placas de forro e blocos. 
As fibras vegetais quando incorporadas em matrizes de cimento promovem melhora na resistência ao impacto, na ductilidade, no controle de fissuras e ajudam na preservação da integridade estrutural do material (Craig, 1986).

Santos (2012) apresenta a composição do tijolo ecológico de papel reciclável a partir da mistura de uma parte de cimento e doze partes de papel reciclado (podendo ser substituído por resíduo da industrialização de papel e celulose) e água, dispensando o processo de queima, constituindo uma solução ecologicamente correta que enfatiza a prática sustentável. Não são mostrados resultados de testes obtidos com essa formulação.

Dentre os principais estudos que utilizam uma metodologia de ensaios similar a que foi adotada no presente trabalho, podem ser destacados: Grande (2003), Pedroti (2007) e Dias Junior (2011).

Grande (2003) apresenta uma metodologia experimental para avaliação do comportamento de tijolos modulares de solocimento e solo-cimento-sílica. Dentre as propriedades estudadas em seu trabalho estão a absorção de água e a durabilidade através de ciclos de molhagem e secagem.

Pedroti (2007) propôs a confecção de blocos cerâmicos prensados em vez do processo de extrusão e fez a comparação com blocos cerâmicos extrudados e com blocos de solo-cimento. Em sua pesquisa, realizou ensaios de absorção de água, durabilidade por molhagem e secagem e desgaste com slake durability, dentre outros.

Dias Junior (2011) fez um estudo com tijolos prensados obtidos a partir de um compósito de cimento, pó de rocha calcária, areia e água, tendo verificado diversas propriedades incluindo a capacidade de absorção de água e a durabilidade por desgaste usando slake durability.

Existem outras pesquisas voltadas à avaliação da durabilidade de materiais, em especial rochas, empregando o slake durability. Dentre alguns trabalhos relevantes estão os de Agustawijaya (2003), que utilizou o equipamento para ensaiar rochas brandas e observou mudanças significativas em seus resultados por conta das diversas geometrias testadas dos corpos de prova; Fuenkajorn e Scri-In (2007), tendo verificado alterações físicas em várias rochas, além de mudança na resistência mecânica, com durabilidade satisfatória e; Yagiz (2010), que utilizou o ensaio para estudar o comportamento de rochas sedimentares, estabelecendo a correlação entre os resultados para diferentes ciclos.

Dias Filho, Xavier e Maia (2013) analisaram a durabilidade de um gnaisse utilizando o ensaio com o referido equipamento. $\mathrm{Na}$ pesquisa foram variados os níveis de desgaste a partir da mudança nas velocidades de rotação, até a observância do aprisionamento, por inércia, das amostras na parede do equipamento. A perda de massa foi aumentando à medida que as rotações foram elevadas, devido ao maior atrito entre as partículas.

Ressalta-se, pois, que a partir de uma determinada frequência, tende-se a uma estabilização acompanhada de uma redução da perda de massa. Isso acontece por conta do aumento da força centrífuga que promove a redução da mobilidade relativa entre as partículas até o momento em que as partículas ficam completamente imobilizadas na parede da câmara. Conforme Dias Filho, Xavier e Maia (2013), a partir desse momento o ensaio perde eficiência e deixa de representar uma condição de campo.

Em termos práticos, o aumento da energia de desgaste no ensaio em laboratório simula locais em que o intemperismo se manifesta de modo mais intenso.

O ensaio de desgaste utilizando o slake durability é geralmente utilizado para materiais rochosos de baixa resistência, entretanto, Xavier (2006) aponta que ele pode ser utilizado para materiais cerâmicos.

\section{METODOLOGIA}

\subsection{MATERIAIS UTILIZADOS E PROPORÇÕES PRODUZIDAS}

Para a confecção dos tijolos foram utilizados os seguintes materiais: cimento Portland de alta resistência inicial (CP V ARI); papel reciclável do tipo jornal, conseguido através de doação pelo Instituto Federal Fluminense (IFF); argila, adquirida 
comercialmente em depósito de construção e; água, da rede pública de abastecimento local.

O cimento Portland de alta resistência inicial (CP V ARI), apesar da dificuldade de obtenção no mercado local e do custo mais elevado em relação aos outros tipos, foi escolhido pela sua larga aplicação na literatura por conta da possibilidade de desforma rápida e de seu alcance de resistência inicial elevada, devido à dosagem em maiores proporções de calcário e argila na produção do clínquer.

Canovas, Kaniche e Seiva (1990) afirmam que os cimentos de pega rápida reduzem consideravelmente a deterioração das fibras vegetais.

Na Tabela 1 são apresentados os quatro tipos de proporções na sequência cimento(C) : jornal(J) : argila(A) : água(a).

\begin{tabular}{ccc|}
\hline \multicolumn{2}{|c|}{ TABELA 1: Tipos de proporções. } \\
\hline $\begin{array}{c}\text { Modo de } \\
\text { incorporação } \\
\text { do jornal }\end{array}$ & Tipo & $\begin{array}{c}\text { Proporção } \\
\text { (C:J:A:a) }\end{array}$ \\
\hline Seco & $\mathbf{T}_{\mathbf{1}}$ & $1: 6: 0: 4$ \\
& $\mathbf{T}_{\mathbf{2}}$ & $1: 6: 0: 2$ \\
\hline Úmido & $\mathbf{T}_{\mathbf{3}}$ & $1: 2: 1: 0$ \\
& $\mathbf{T}_{\mathbf{4}}$ & $1: 2: 0: 0$ \\
\hline & & FONTE: Autoria própria.
\end{tabular}

Os tipos secos são aqueles em que a massa de jornal empregada é triturada após secagem em estufa durante 48 horas e a água é adicionada durante a mistura de todos os componentes. Os tipos úmidos são aqueles em que a polpa de jornal é empregada contendo água residual do peneiramento da massa após passar por triturador industrial, sem a etapa de secagem em estufa, não requerendo adição de água na mistura dos componentes.

A argila foi utilizada apenas no tipo $T_{3}$ no intuito de avaliar as possíveis contribuições deste componente a partir de um comparativo com o compósito $\mathrm{T}_{4}$, que não apresenta esse componente em sua constituição.

O termo "tipo de proporção" foi utilizado em vez de "traço", por este último estar relacionado às proporções em massa obtidas a partir de um critério de dosagem específico, não empregado aqui.

\subsection{PROCESSO DE PRODUÇÃO DOS TIJOLOS PRENSADOS}

Na Figura 1 apresenta-se um fluxograma com todas as etapas do processo de produção dos tijolos prensados utilizando as massas de jornal secas e úmidas.

Na Figura 2 ilustram-se todas as etapas [a] a [j] do processo produtivo, indicadas no fluxograma da Figura 1.

A fragmentação do jornal a seco foi feita em fragmentadora de papel. Após a realização desta etapa, o material foi colocado em tonel com água durante 48 horas a fim de obter aspecto de desmanche ao toque. Procedeu-se à fragmentação do produto resultante em liquidificador industrial basculante junto com a água residual do tonel, triturando-o durante cerca de dois minutos e peneirando-o para a retirada manual do excesso de água.

Para a confecção dos tipos úmidos, levouse a polpa úmida resultante desse peneiramento imediatamente até a etapa de mistura dos componentes, evitando a perda de água constituinte. Para o outro modo de incorporação do resíduo na mistura, a polpa resultante do peneiramento foi colocada em estufa a $110^{\circ} \mathrm{C}$ durante 48 horas até a secagem total do material, procedendo-se, então, à fragmentação do material seco em liquidificador doméstico para obtenção de partículas ainda menores do papel.

Os materiais foram colocados em uma batedeira industrial planetária obedecendo à sequência cimento, jornal, argila e, por fim, água, garantindo uma maior homogeneização da mistura e, posteriormente, foi feita a moldagem dos tijolos utilizando uma prensa manual.

A prensa tem capacidade de produção de dois tijolos prismáticos simultaneamente, com as dimensões $20 \times 10 \times 5 \mathrm{~cm}$, contendo dois furos de 5 $\mathrm{cm}$ de diâmetro e área útil de $80 \%$. Seguiram-se as prescrições da NBR 8491 (ABNT, 2012) para tijolos de solo-cimento, em virtude da inexistência de normas específicas para o material proposto.

A mistura era compactada manualmente nos moldes da prensa. Em seguida foi realizada a prensagem, levando-se a alavanca até a posição horizontal, correspondente ao ponto de máxima compactação da mistura, para a obtenção de tijolos 
com dimensões normatizadas. Nos casos em que a análise dimensional dos tijolos não atendia às especificações da NBR 8491 (ABNT, 2012), o material era reutilizado, retornando à etapa de prensagem.

Empregou-se a cura seca, dispensando a cura em câmara úmida, por conta da umidade retida pelas fibras vegetais presentes no papel, como sugerido por Nolasco (1993).

$\mathrm{Na}$ Figura 3 têm-se os quatro tipos de tijolos obtidos após a realização do processo de cura.
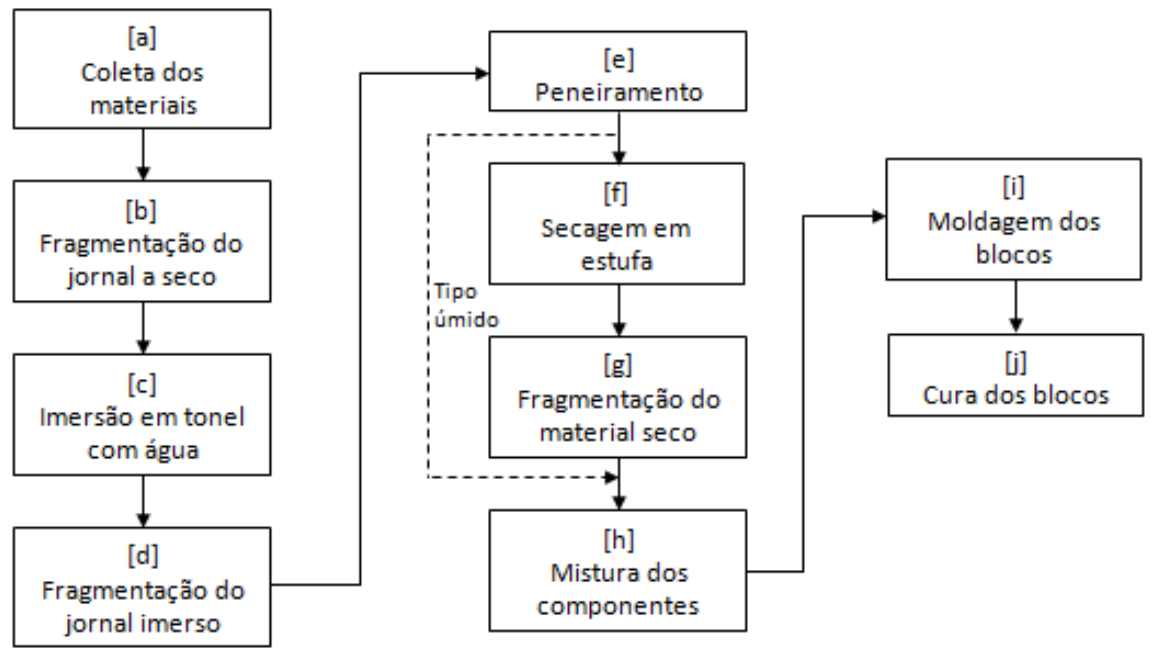

FIGURA 1: Fluxograma do processo de produção dos tijolos.

FONTE: Autoria própria.

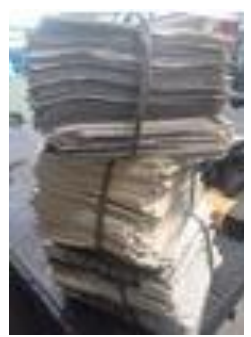

[a]

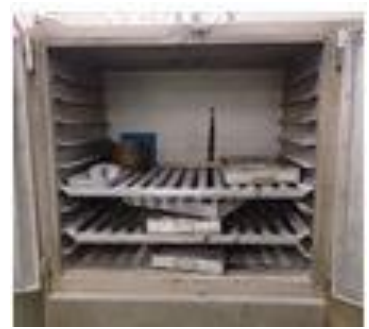

[f]

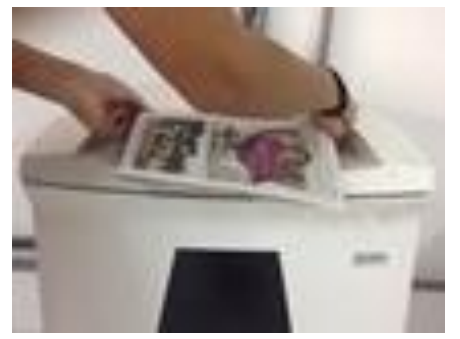

[b]

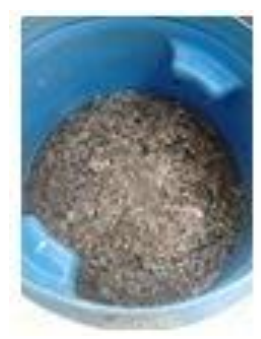

[c]

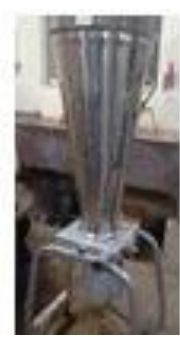

[d]

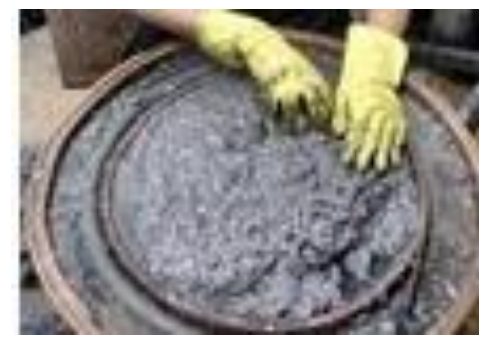

[e]

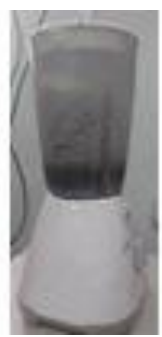

[g]

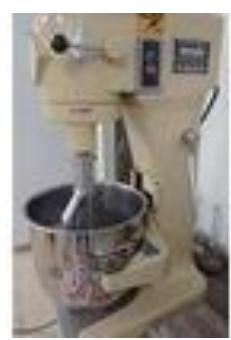

[h]

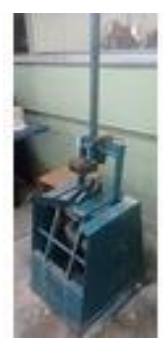

[i]

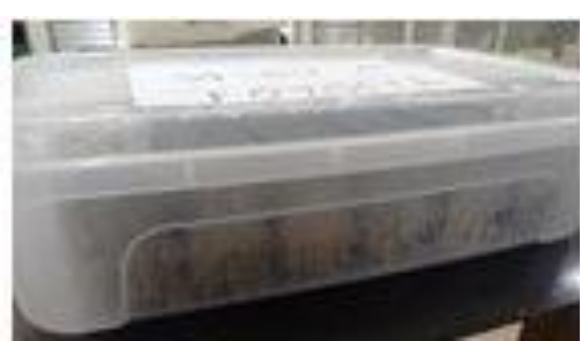

[j]

FIGURA 2: Etapas do processo de produção dos tijolos, sendo: [a] Coleta dos materiais; [b] Fragmentação do jornal a seco; [c] Imersão em tonel com água; [d] Fragmentação do jornal imerso; [e] Peneiramento; [f] Secagem em estufa; [g] Fragmentação do material seco; [h] Mistura dos componentes; [i] Moldagem dos blocos; [j] Cura dos blocos. FONTE: Autoria própria.

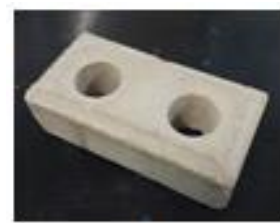

[a]

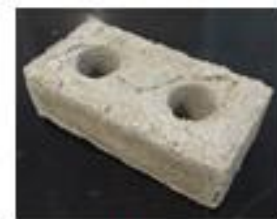

[b]

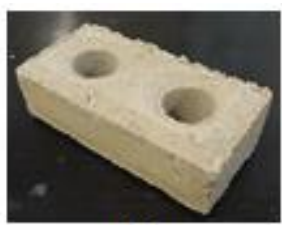

[c]

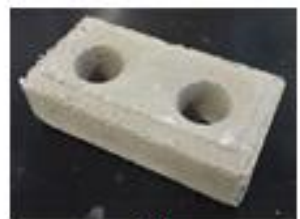

[d]

FIGURA 3: Amostras de tijolos após o processo de cura, pertencentes aos tipos: [a] $\mathrm{T}_{1} ;[\mathrm{b}] \mathrm{T}_{2}$; [c] $\mathrm{T}_{3}$; [d] $\mathrm{T}_{4}$. FONTE: Autoria própria. 


\subsection{ENSAIOS DE ABSORÇÃO DE ÁGUA E DURABILIDADE DOS TIJOLOS}

O comportamento do material proposto é avaliado quanto à capacidade de absorção de água e, também, quanto à durabilidade, medida nos ensaios de molhagem e secagem e através do ensaio de desgaste utilizando slake durability, tendo como parâmetro indicativo a perda de massa resultante em cada ensaio realizado

\subsubsection{Amostras empregadas nos ensaios}

Para a realização dos ensaios de absorção de água foram confeccionados seis corpos de prova para cada tipo de proporção, sendo utilizados três em cada uma das idades avaliadas: 28 e 91 dias. Para os ensaios de durabilidade por ciclos de molhagem e secagem, também foram confeccionados seis corpos de prova para cada tipo, por conta das duas idades. Os corpos de prova desses ensaios consistiram em amostras intactas de tijolos, após a realização do processo de cura, como ilustradas na Figura 3. E, para a realização do ensaio de desgaste, ocorrido em apenas uma idade (28 dias), foi confeccionado um corpo de prova de cada tipo e deste foram retiradas dez partículas com massa individual de 40 a $60 \mathrm{~g}$, a partir da amostra oriunda do processo de cura. Portanto, foram necessários treze tijolos de cada tipo de proporção para a efetivação de todos os ensaios.

\subsubsection{Ensaio de absorção de água}

Com a falta de normas específicas para o material estudado e devido à similaridade de tipo e dimensões dos tijolos ecológicos de papel reciclável com os tijolos de solo-cimento, os ensaios de absorção de água foram regidos pela NBR 8492 (ABNT, 2012).

Para o cálculo dos valores individuais de absorção de água utilizou-se a Equação 1:

$$
A=\frac{m_{2}-m_{1}}{m_{1}} \times 100
$$

\section{Sendo:}

$A$ o valor individual de absorção de água, em \%; $m_{1}$ a massa do corpo de prova seco em estufa, em $\mathrm{g}$; $m_{2}$ a massa do corpo de prova saturado, em g.
A referida norma define como indicativo de controle de qualidade dos tijolos de solo-cimento os limites máximos de $22 \%$ e de $20 \%$ para os valores individuais e médios de absorção de água, respectivamente.

A realização do ensaio para avaliação da capacidade de absorção de água dos tijolos consiste na secagem do tijolo em estufa a $110^{\circ} \mathrm{C}$, na pesagem do corpo de prova seco, na imersão do tijolo em água durante 24 horas e na pesagem do corpo de prova saturado.

Foram preparados três corpos de prova de cada tipo para a realização dos ensaios em cada uma das idades: aos 28 e aos 91 dias.

\subsubsection{Ensaio de durabilidade por molhagem e secagem}

Este ensaio segue a NBR 13554 (ABNT, 1996) para tijolos de solo-cimento e atribui a perda de massa como parâmetro indicativo da durabilidade do material.

A norma recomenda a preparação de três corpos de prova, no qual são avaliadas a variação de volume no corpo 1 e a perda de massa nos corpos 2 e 3 .

Para a execução do ensaio deve-se determinar o volume inicial do corpo de prova 1 , além da massa e do volume do mesmo após todos os corpos de prova passarem por um processo de cura durante sete dias em câmara úmida. Recomenda-se, ainda, a colocação dos corpos de prova imersos em água durante cinco horas. Determina-se novamente a massa e o volume do corpo 1 após a retirada do excesso superficial de água. Em seguida os três corpos de prova devem ser colocados na estufa a uma temperatura de $(71 \pm 2)^{\circ} \mathrm{C}$ durante 42 horas e, mais uma vez, obtêm-se a massa e o volume do primeiro corpo de prova.

Para os corpos de prova 2 e 3 deve-se proceder com uma escovação total e firme das superfícies dos mesmos equivalente a $15 \mathrm{~N}$, sendo 18 a 20 escovações verticais para a área lateral e quatro escovações para cada uma das bases, sendo duas em cada uma das direções ortogonais. 0 tempo de retirada da estufa e realização das escovações não deve ser superior a uma hora. 
O procedimento a partir da imersão dos corpos de prova em água durante cinco horas até a escovação dos mesmos, que constitui um ciclo de 48 horas, deve ser repetido mais cinco vezes. Após os seis ciclos realizados, levam-se os corpos de prova à temperatura entre $105^{\circ} \mathrm{C}$ a $110^{\circ} \mathrm{C}$ até atingirem a constância de massa.

Para a obtenção da perda de massa nos outros dois corpos de prova, parte-se do cálculo da quantidade relativa de água nos mesmos após atingirem massa constante. Admite-se que esse valor corresponde à água retida no corpo de prova 1, calculado conforme a Equação 2:

$$
A=\frac{m_{f(1)}-m_{i(1)}}{m_{i(1)}}
$$

Sendo:

$A$ a água retida no corpo de prova 1;

$m_{f(1)}$ a massa seca final do corpo de prova 1 após atingir massa constante, em g;

$m_{i(1)}$ a massa seca inicial do corpo de prova 1, calculada por ocasião da moldagem, em g.

Além disso, deve-se fazer a correção das massas secas dos corpos de prova, descontando a água que reagiu com o cimento e o solo (no caso o jornal) durante o ensaio e que ficou retida no primeiro corpo de prova a $110^{\circ} \mathrm{C}$. Usa-se a Equação 3:

$$
m_{f c(2,3)}=\frac{m_{f(2,3)}}{A+1}
$$

Sendo:

$m_{f c(2,3)}$ é a massa seca final corrigida dos corpos de prova 2 e 3 , em g;

$m_{f(2,3)}$ é a massa seca final dos corpos de prova 2 e 3 após atingirem massa constante, em g;

$A$ é a água retida no corpo de prova 1.

Finalmente, calcula-se a perda de massa dos corpos de prova 2 e 3 como porcentagem da massa seca inicial, conforme a Equação 4:

$$
P_{m(2,3)}=\frac{m_{i(2,3)}-m_{f c(2,3)}}{m_{i(2,3)}} \times 100 \quad \text { Eq. [4] }
$$

Sendo:

\footnotetext{
$m_{i(2,3)}$ a massa seca inicial calculada por ocasião da moldagem dos corpos de prova 2 e 3 , em g;
}

$m_{f c(2,3)}$ a massa seca final corrigida dos corpos de prova 2 e 3, em g;

$P_{m(2,3)}$ a perda de massa dos corpos de prova 2 e 3, em $\%$.

De acordo com a ABCP (1980), a perda de massa dos tijolos de solo-cimento não deve ser superior a $10 \%$ após todos os ciclos de molhagem e secagem.

Para a execução dos ensaios, o processo de cura úmida durante sete dias não foi levado em consideração, pelo fato desse tipo de cura não ter sido empregado na pesquisa. A escovação dos tijolos também não foi realizada, uma vez que as solicitações de abrasão na superfície das paredes não são tão severas como aquelas previstas em outros usos do compósito confeccionado, conforme comentado por Grande (2003) para o caso do solocimento.

Foram preparados três corpos de prova de cada tipo para serem ensaiados em cada uma das idades: aos 28 e aos 91 dias.

\subsubsection{Ensaio de desgaste utilizando slake durability}

O uso do aparelho slake durability permite a avaliação da durabilidade do material tendo como parâmetro a perda de massa por conta do desgaste por atrito, a partir de um comparativo com os parâmetros do material no estado intacto. Os procedimentos são descritos pela norma americana D4644 (ASTM, 1987).

O ensaio consiste em submeter o corpo de prova que é constituído por 10 partículas com massa individual variando de 40 a $60 \mathrm{~g}$ a um processo de baixa energia de desgaste superficial. $O$ corpo de prova é colocado em um cilindro de malha metálica que gira em torno de seu eixo horizontal dentro de uma câmara onde fica parcialmente submerso em água sendo lavado, sofrendo desgaste por abrasão entre as partículas e com a parede do cilindro. 0 contato das partículas com a água favorece a desagregação por desgaste.

$\mathrm{Na}$ Figura 4 têm-se $\mathrm{o}$ conjunto de partículas a serem desgastadas dentro do cilindro metálico e a câmara com o cilindro. $O$ equipamento ilustrado pertence ao Laboratório de Ensaios de 
Durabilidade (LED) da Universidade Estadual do Norte Fluminense Darcy Ribeiro (UENF), onde os ensaios foram realizados.

Maia (2001) sugere como resultado da prévia de desgaste a avaliação da perda de massa após a realização do 5으 ciclo de ensaio.

Para o cálculo da perda de massa usa-se a massa inicial do conjunto antes da realização do 10 ciclo e a massa final após a realização de determinado ciclo. Por ocasião da realização do 5 o ciclo, tem-se a Equação 5:

$$
P_{m}=\frac{m_{5}-m_{0}}{m_{0}} \times 100
$$

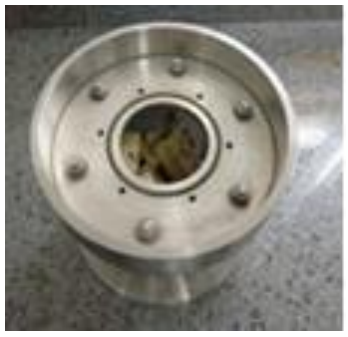

[a]
Sendo:

$P_{m}$ a perda de massa, em \%;

$m_{5}$ a massa final obtida após a realização do 5 은 ciclo, em g;

$m_{0}$ a massa inicial do conjunto antes da realização do 1 o ciclo, em g.

Na Tabela 2, adaptada de Gamble (1971) e Maia (2001), tem-se uma classificação da durabilidade de materiais rochosos relacionada com a perda de massa após a realização dos ciclos de desgaste.

FIGURA 4: Ensaio de desgaste: [a] conjunto de partículas no cilindro; [b] cilindro no tanque. FONTE: Autoria própria.

TABELA 2: Classificação da durabilidade de rochas em função da perda de massa no ensaio.

\begin{tabular}{cccc}
$\begin{array}{c}\text { Classificação da } \\
\text { durabilidade }\end{array}$ & $\mathbf{1 0}$ ciclo & Perda de massa (\%) \\
\hline Muito alta & $<1$ & $\mathbf{2 0}$ ciclo & $\mathbf{5 0}$ ciclo \\
\hline Alta & $1-2$ & $<2$ & $<5$ \\
\hline Medianamente alta & $2-5$ & $5-15$ & $5-15$ \\
\hline Média & $5-15$ & $15-40$ & $15-40$ \\
\hline Baixa & $15-40$ & $40-70$ & $40-70$ \\
\hline Muito baixa & $>40$ & $>70$ & $70-80$ \\
\hline & & FONTE: adaptado de Gamble (1971) e Maia (2001).
\end{tabular}

Foram ensaiados corpos de prova de todos os tipos aos 28 dias. Aqui, a energia de desgaste não foi modificada, sendo admitida frequência correspondente a 20 rotações por minuto. Cada ciclo teve um período de 10 minutos.

\section{RESULTADOS}

Os resultados da absorção de água e das perdas de massa obtidas através dos ensaios de durabilidade por molhagem e secagem e de desgaste utilizando slake durability estão apresentados na Tabela 3 para todos os tipos e idades avaliadas.

\subsection{ABSORÇÃO DE ÁGUA}

Na Figura 5 tem-se a representação gráfica das capacidades de absorção de água de todos os tipos aos 28 e aos 91 dias de idade.

Verifica-se que todos os tipos confeccionados apresentaram valores médios de 
absorção de água superiores ao limite imposto pela NBR 8491 (ABNT, 2012) correspondente a 20\%, o que poderia restringir o uso dos tijolos para a construção de paredes externas, entretanto, o problema pode ser resolvido com a utilização de revestimentos e impermeabilizantes.

Os tipos $T_{3}$ e $T_{4}$, que empregam polpa úmida e maiores teores de cimento na composição, foram os que apresentaram os valores mais reduzidos nas duas idades avaliadas, por conta da diminuição da porosidade do compósito associada ao cimento. Para esses tipos, enfatiza-se, ainda, que não houve diferença significativa entre os resultados de um mesmo tipo para as duas idades e nem entre os tipos.

Estabelecendo um comparativo entre os tipos $T_{1}$ e $T_{2}$, diferentes na quantidade de água, levando em consideração as duas idades, observase que no primeiro tipo há um aumento da capacidade de absorção, sendo este tipo constituído naturalmente do maior teor de água e, no outro há uma diminuição dessa capacidade. Isso pode estar associado a uma perda mais rápida da água de constituição dos tijolos do tipo $T_{1}$, deixando mais espaços vazios quando da realização do ensaio de absorção de água aos 91 dias.

Pedroti (2007) encontrou valor médio de absorção de água de 31,85\% para tijolos cerâmicos prensados e queimados e de $24,18 \%$ para tijolos de solo-cimento, bem próximos dos resultados encontrados para os últimos tipos no presente estudo.

É válido ressaltar que nenhum tijolo apresentou qualquer tipo de desagregação nem deformação ao longo e após a realização dos ensaios nas duas idades estudadas.

\subsection{DURABILIDADE POR MOLHAGEM E SECAGEM}

$\mathrm{Na}$ Figura 6 tem-se a representação gráfica das perdas de massa para todos os tipos confeccionados, resultantes dos ensaios de durabilidade por molhagem e secagem realizados aos 28 e aos 91 dias de idade dos tijolos.

\begin{tabular}{|c|c|c|c|c|c|}
\hline \multirow[t]{2}{*}{ Tіро } & \multicolumn{2}{|c|}{ Absorção de água (\%) } & \multicolumn{2}{|c|}{$\begin{array}{l}\text { Perda de massa por } \\
\text { durabilidade (\%) }\end{array}$} & \multirow{2}{*}{$\begin{array}{l}\text { Perda de massa } \\
\text { no 50 ciclo por } \\
\text { desgaste (\%) }\end{array}$} \\
\hline & 28 dias & 91 dias & 28 dias & 91 dias & \\
\hline$T_{1}$ & 53,08 & 63,14 & 7,63 & 6,05 & 14,90 \\
\hline$T_{2}$ & 62,91 & 43,93 & 12,84 & 5,22 & 17,84 \\
\hline$T_{3}$ & 28,82 & 29,03 & 4,14 & 3,78 & 10,68 \\
\hline$T_{4}$ & 29,35 & 24,05 & 5,47 & 2,54 & 12,56 \\
\hline
\end{tabular}

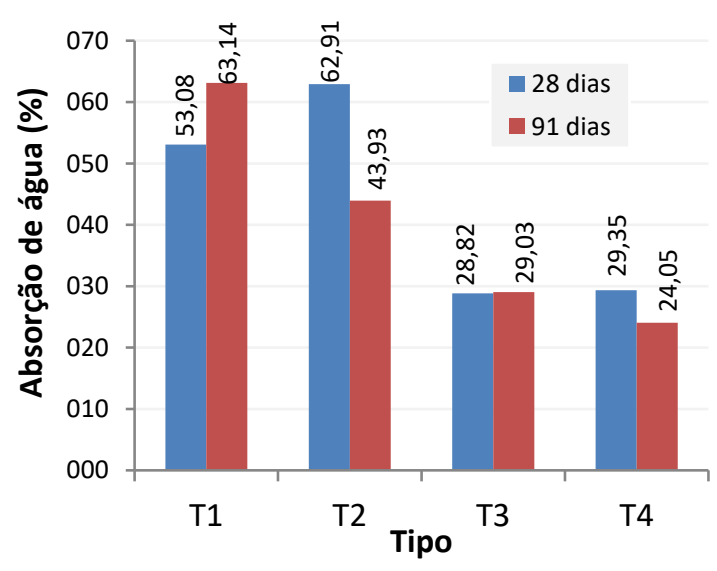

FIGURA 5: Capacidade de absorção de água nas duas idades avaliadas.

FONTE: Autoria própria.

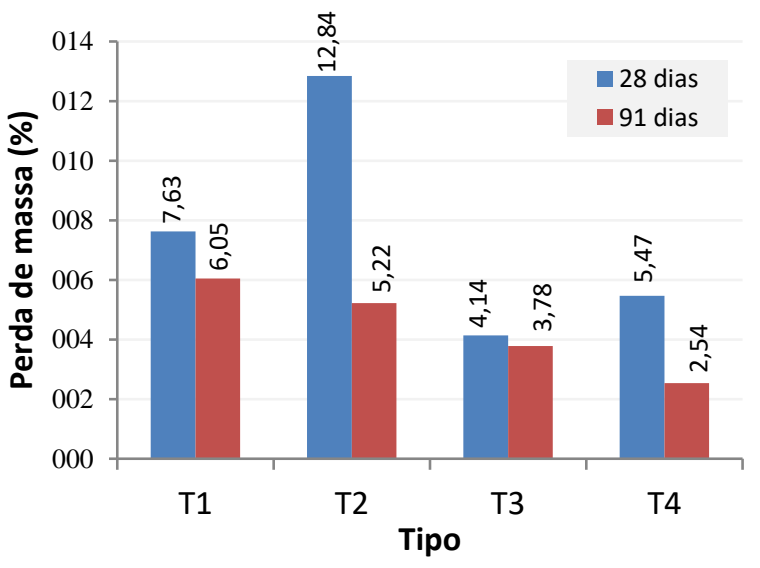

FIGURA 6: Perdas de massa no ensaio de durabilidade por molhagem e secagem nas duas idades avaliadas.

FONTE: Autoria própria 
É possível observar que apenas os tijolos do tipo $T_{2}$ no ensaio aos 28 dias não atenderam ao limite máximo de $10 \%$ de perda de massa imposto pela ABCP (1980), apresentando um valor superior nada significativo.

Os menores valores de perda de massa estão associados, em geral, aos tijolos dos tipos $T_{3} \mathrm{e}$ $\mathrm{T}_{4}$, que apresentam maiores teores de cimento em relação aos outros dois tipos, dificultando a desintegração do material.

Em todos os tipos observa-se a redução da perda de massa com o passar do tempo, podendo ser um indicativo do potencial de desempenho dos tijolos. As reduções significativas do parâmetro avaliado aconteceram nos tijolos dos tipos $T_{2}$ e $T_{4}$. Entretanto, os tijolos do tipo $T_{2}$ não apresentavam boas condições estéticas no ensaio aos 28 dias, com a presença de fissuras e facilmente desintegráveis e, em virtude da natureza tátil do ensaio por molhagem e secagem, perdiam-se muitos fragmentos dos tijolos ao longo dos ciclos do ensaio, o que pode justificar a discrepância entre os resultados para as duas idades.

Na Figura 7 observam-se os aspectos dos tijolos após saírem do último ciclo do ensaio que iniciou aos 28 dias. É possível perceber que apenas os tijolos do tipo $T_{2}$ apresentaram desintegração significativa nessa idade, fato não observado em ensaio posterior, conforme ilustrado na Figura 8.

Pedroti (2007) encontrou valor médio $0,21 \%$ para tijolos de solo-cimento, bem abaixo dos valores obtidos nesse estudo.

\subsection{DESGASTE UTILIZANDO SLAKE DURABILITY}

Na Figura 9 tem-se a representação gráfica das perdas de massa para todos os tipos confeccionados, resultantes do ensaio de desgaste utilizando slake durability realizado aos 28 dias de idade dos tijolos.

Por esse ensaio, os menores valores de perda de massa também estão associados aos tijolos dos tipos $T_{3}$ e $T_{4}$, que apresentam os maiores teores de cimento na composição. E, os maiores valores desse parâmetro estão associados ao tipo $T_{2}$, que pode mais uma vez ter correlação com a sua facilidade de desagregação, conforme observado no ensaio de durabilidade por molhagem e secagem, sendo agora justificada com a lavagem em água durante o processo de desgaste.

Mesmo assim, verifica-se que, seguindo a classificação apresentada na Tabela 2, os tijolos do tipo $T_{2}$ têm durabilidade medianamente alta enquanto os tijolos dos outros tipos apresentam alta durabilidade.

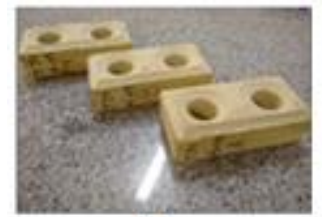

[a]

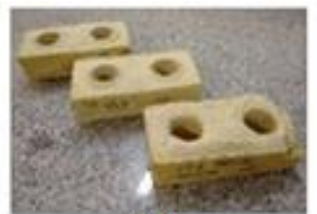

[b]

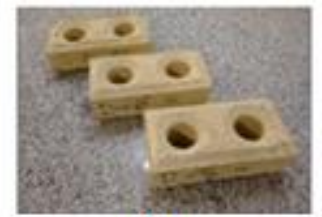

[c]

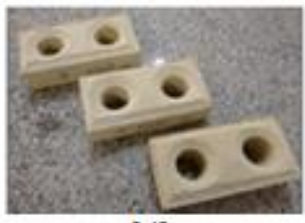

[d]

FIGURA 7: Aspecto após o 60 ciclo do ensaio de durabilidade realizado aos 28 dias de idade dos tijolos pertencentes aos tipos: [a] $\mathrm{T}_{1} ;[\mathrm{b}] \mathrm{T}_{2} ;[\mathrm{c}] \mathrm{T}_{3} ;[\mathrm{d}] \mathrm{T}_{4}$.

FONTE: Autoria própria.

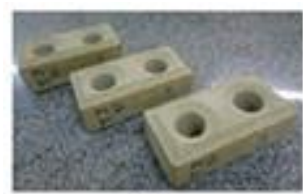

[a]

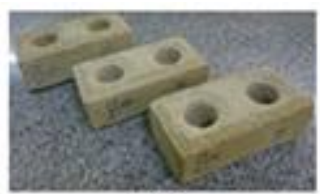

[b]

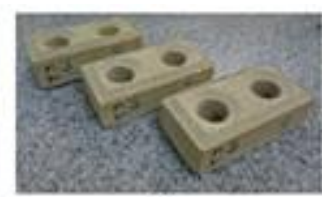

[c]

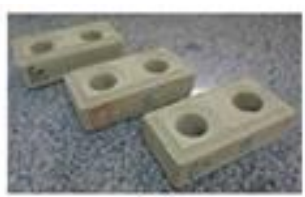

[d]

FIGURA 8: Aspecto após o 6o ciclo do ensaio de durabilidade realizado aos 91 dias de idade dos tijolos pertencentes aos tipos: [a] $\mathrm{T}_{1} ;[\mathrm{b}] \mathrm{T}_{2} ;[\mathrm{c}] \mathrm{T}_{3} ;[\mathrm{d}] \mathrm{T}_{4}$

FONTE: Autoria própria. 
Entre os dois primeiros ciclos, observa-se uma perda de massa mais acentuada para todos os tipos. Entretanto, com o aumento do número de ciclos, é possível perceber uma redução na taxa de aumento do desgaste, provavelmente associada ao arredondamento das arestas da partículas por conta do atrito no ensaio. Este fato também foi observado por Dias Filho, Xavier e Maia (2013) em amostras de gnaisse. A perda de massa nos ciclos iniciais é bem evidenciada devido ao formato cúbico das partículas, que perdem as arestas rapidamente com o atrito na câmara metálica. A perda de massa é reduzida diante do arredondamento das partículas.

Pedroti (2007) encontrou valor médio de perda de massa correspondente a 17,42\% para tijolos de solo-cimento, próximo do resultado obtido para os tijolos do segundo tipo dessa pesquisa. Dias Junior (2011) encontrou valores médios que variaram de $24,70 \%$ e chegaram a cerca de $80,00 \%$. Dias Filho, Xavier e Maia (2013) encontraram valor médio em torno de $2,00 \%$ para o gnaisse em seu estado intacto, utilizando a mesma frequência de ensaio desse estudo.

$\mathrm{Na}$ Figura 10 observam-se os aspectos dos tijolos após saírem do 1으 (à esquerda) e do 50 (à direita) ciclos do ensaio. Nota-se que os corpos de prova do tipo $T_{2}$ apresentaram desintegração desde a saída do primeiro ciclo.

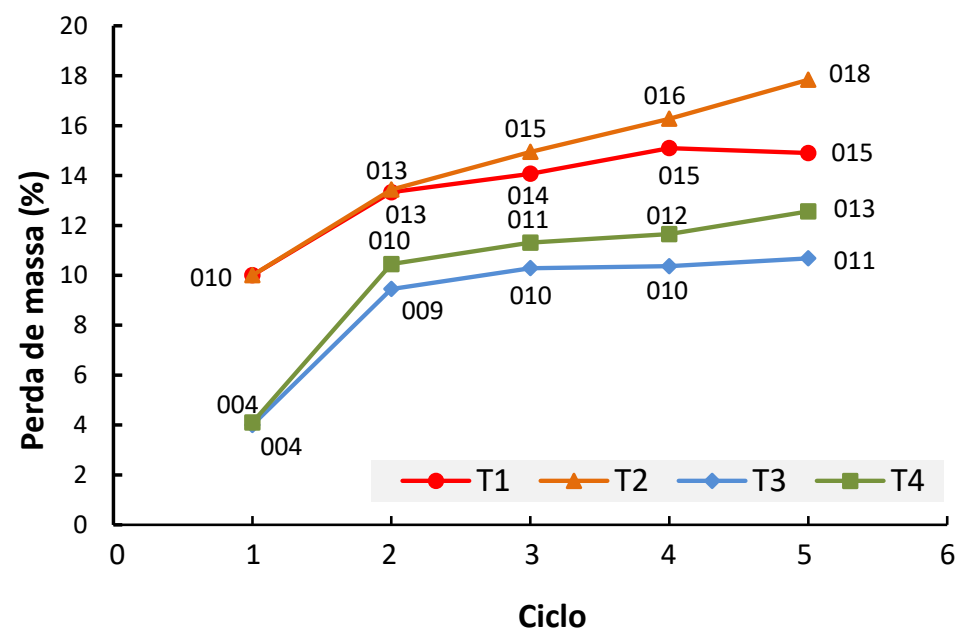

FIGURA 9: Perdas de massa no ensaio de desgaste com slake durability aos 28 dias de idade. FONTE: Autoria própria.
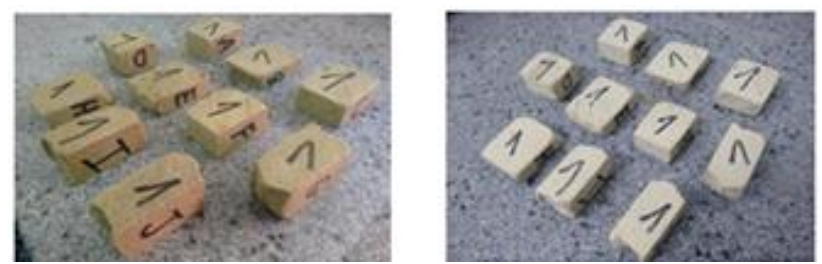

[a]
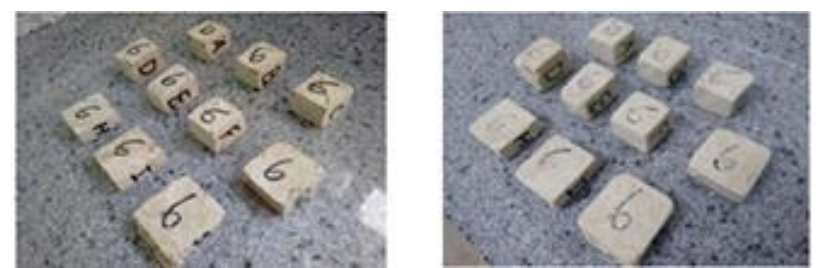

[c]
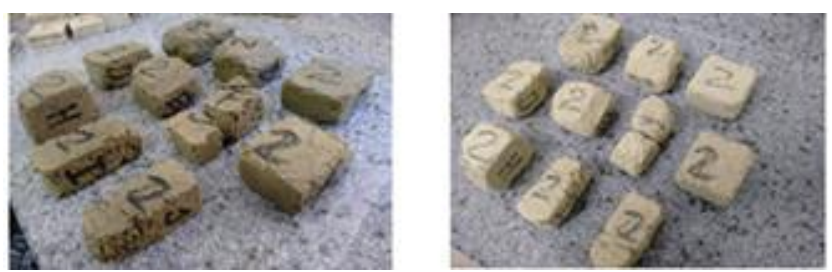

[b]
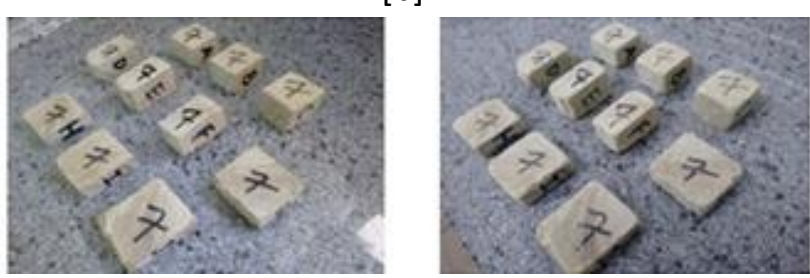

[d]

FIGURA 10: Aspectos após o 10 (à esquerda) e o 5o (à direita) ciclos do ensaio de desgaste dos tijolos pertencentes aos tipos: [a] $\mathrm{T}_{1} ;[\mathrm{b}] \mathrm{T}_{2} ;[\mathrm{c}] \mathrm{T}_{3} ;[\mathrm{d}] \mathrm{T}_{4}$.

FONTE: Autoria própria. 


\section{CONCLUSÕES}

Este trabalho propôs o desenvolvimento de um material de construção do tipo tijolo ecológico de papel reciclável, tendo como matériaprima base o jornal. O material foi avaliado nos critérios físicos e de desempenho a partir de ensaios de avaliação da capacidade de absorção de água e de durabilidade por ciclos de imersão em água e secagem e por desgaste.

O material apresentado corrobora com a busca por novos conceitos e soluções técnicas visando a sustentabilidade das atividades da construção civil, enfatizando a minimização do consumo de recursos naturais por meio da reciclagem de resíduos, inclusive o papel que é altamente descartável nos lixos urbanos e, dispensando o processo de queima.

O emprego do papel na composição do material contribui na redução do seu custo, o que o torna viável principalmente para a construção de moradias de interesse social.

Todos os tipos confeccionados não atenderam ao limite máximo de absorção de água de $20 \%$ imposto na NBR 8491 (ABNT, 2012). Porém, este fator não é preocupante, já que o problema pode ser resolvido com o uso de tratamentos impermeabilizantes. As menores capacidades de absorção de água estão associadas aos últimos tipos, que apresentam os maiores teores de cimento na composição. $E$, houve diferença significativa entre os resultados dos ensaios aos 28 e aos 91 dias apenas para os dois primeiros tipos.

Nos ensaios de avaliação da durabilidade por ciclos de imersão em água e secagem, pode-se dizer que, de um modo geral, os tipos atenderam satisfatoriamente ao limite máximo de $10 \%$ de perda de massa imposto pela ABCP (1980), apesar da maior desintegração dos tijolos do segundo tipo verificada no ensaio aos 28 dias. Observou-se, ainda, que houve diminuição da perda de massa nos ensaios realizados aos 91 dias.

A partir dos ensaios de avaliação da durabilidade por meio do desgaste utilizando o slake durability, os tijolos foram classificados, em sua maioria, com alta durabilidade, estando as menores perdas de massa novamente associadas aos últimos tipos, que têm os maiores teores de cimento. Esse ensaio foi feito apenas aos 28 dias de idade dos tijolos. É válido ressaltar que não houve dificuldades em realizar o ensaio com o material, apesar de sua natureza não ser intrinsecamente de um material rochoso.

O uso do papel jornal na constituição do compósito conduziu a resultados satisfatórios, potencializando o novo material do ponto de vista da análise física a partir da absorção de água e da análise de desempenho através da durabilidade, como alternativa ao uso do tijolo cerâmico, de cimento e de solo-cimento, possibilitando a redução dos custos das obras, a reciclagem de resíduos (papel), a diminuição da degradação ambiental oriunda dos processos de extração das matériasprimas e do beneficiamento dos produtos citados.

Para o prosseguimento da pesquisa, sugere-se a realização dos ensaios de absorção de água e durabilidade em idades mais avançadas. Além disso, para levar em consideração os diferentes níveis de intemperismo, torna-se interessante a realização de ensaios considerando diversas energias de desgaste a partir da modificação das velocidades de rotação do equipamento. Isso é importante uma vez que um mesmo material nem sempre é apropriado para todas as condições intempéricas.

A presente pesquisa enquadra-se no contexto da sustentabilidade na construção civil pela possibilidade de reciclagem de material, pela dispensa de queima na produção dos tijolos e pela minimização dos desperdícios no canteiro de obras associada ao sistema modular, contribuindo, dessa forma, para a diminuição da degradação do meio ambiente e do déficit habitacional.

\section{REFERÊNCIAS BIBLIOGRÁFICAS}

AGUSTAWIJAYA, D. S. Modeled Mechanisms in The Slake-Durability Test For Soft Rocks. Lecturer, Department of Civil Engineering, Faculty of Engineering Mataram University, Dimensi Teknik Sipil, Vol. $5-n^{\circ} 2$, 2003, 87-92 p.

AMERICAN SOCIETY FOR TESTING AND MATERIALS (ASTM), D4644: Slake Durability of Shales and Similar Weak Rocks. 1987.

ASSOCIAÇÃO BRASILEIRA DE CIMENTO PORTLAND, Dosagem das misturas de solo-cimento: normas de 
dosagem e métodos de ensaio. Publicações $A B C P$, São Paulo, 1980.

ASSOCIAÇÃO BRASILEIRA DE NORMAS TÉCNICAS, NBR 13554: Tijolo de solo-cimento: Ensaio de durabilidade por molhagem e secagem. Rio de Janeiro, 1996.

NBR 8491: Tijolo de solo-cimento: Requisitos. Rio de Janeiro, 2012.

NBR 8492: Tijolo de solo-cimento: Análise dimensional, determinação da resistência à compressão e da absorção de água: Método de ensaio. Rio de Janeiro, 2012.

CANOVAS, M. E. et al. Possible ways of preventing deterioration of vegetable fibres in cement mortars. In: SOBRAL, H. S. (Ed.). Vegetable plants and ther fibres as building materials. 1a Ed., London, Chapman and Hall, 1990, 120-129 p.

CRAIG, R. J. Construction with reinforced fibre concrete. In: International Conference on Materials of Construction for Developing Countries. Bankok, London, 1978, 20212027 p.

DIAS FILHO, J. L. E. et al. Análise da durabilidade de gnaisse através de ensaio de desgaste. Vértices. Campos dos Goytacazes, Vol. $15-n^{\circ}$ 3, 2013, 7-16 p.

DIAS JUNIOR, N. S. Produção de blocos prensados e de encaixe com pó de pedra do beneficiamento de rochas calcárias. Dissertação (Mestrado em Engenharia Civil) Universidade Estadual do Norte Fluminense Darcy Ribeiro. Campos dos Goytacazes, RJ, 2011, 91 p.

FUENKAJORN, K. et al. Slake durability index and strength testing of some rocks in Thailand. Geomechanics Research Unit, Suranaree University of Technology, Thailand, 2007, 15 p.

GAMBLE, J. C. Durability-plasticity classification of shales and other argillaceous rock. Ph.D. Thesis - University of Illinois, 1971.

GRANDE, F. M. Fabricação de tijolos modulares de solocimento por prensagem manual com e sem adição de sílica ativa. Dissertação (Mestrado em Arquitetura) Universidade de São Paulo. São Paulo, SP, 2003, 165 p.

JOHN, V. M. A construção, o meio ambiente e a reciclagem. 2008 Disponível em: http://www.placogyps.com.br/download/A\%20Constru \%E7\%E3o\%20Civil\%20e\%20o\%20Meio\%20Ambiente.pdf . Acesso em: 20 out. 2015.

LOPES, W. G. R. Solo-cimento reforçado com bambu: características físico-mecânicas. Tese (Doutorado em Engenharia Agrícola) - Universidade Estadual de Campinas. Campinas, SP, 2002, 158 p.

MAIA, P. C. A. Comportamento Geomecânico e de Alterabilidade de Enrocamentos. Tese (Doutorado
Engenharia Civil) - Pontifícia Universidade Católica do Rio de Janeiro. Rio de Janeiro, RJ, 2001.

NOLASCO, A. M. Utilização de resíduos da indústria de papel na produção de materiais para a construção civil. Dissertação (Mestrado em Arquitetura) - Universidade de São Paulo. São Paulo, SP, 1993.

PEDROTI, L. G. Estudo de conformidades em relação à ABNT de blocos cerâmicos prensados e queimados. Dissertação (Mestrado em Engenharia Civil) Universidade Estadual do Norte Fluminense Darcy Ribeiro. Campos dos Goytacazes, RJ, 2007, 106 p.

SANTOS, J. C. Patente no PI 1003663-6 A2. Brasil, 2012.

SOUZA, M. I. B. et al. Tijolos prensados de solo-cimento confeccionados com resíduos de concreto. Revista Brasileira de Engenharia Agrícola e Ambiental. Campina Grande, Vol. $12-n^{\circ} 2,2008,205-212$ p.

XAVIER, G. C. Resistência, Alterabilidade e Durabilidade de Peças Cerâmicas Vermelhas Incorporadas com Resíduo de Granito. Tese (Doutorado em Engenharia Civil) - Universidade Estadual do Norte Fluminense Darcy Ribeiro. Campos dos Goytacazes, RJ, 2006.

YAGIZ, S. Correlation between slake durability and rockproperties for some carbonate rocks. Bull Eng Geol Environ, Vol. 70, 2010, 377-383 p. 